Construction \& Building Materials

Elsevier Editorial System(tm) for

Manuscript Draft

Manuscript Number: CONBUILDMAT-D-17-01550R1

Title: Magnesium Phosphate Cements formulated with Low Grade Magnesium oxide incorporating Phase Change Materials for thermal energy storage

Article Type: Research Paper

Keywords: Magnesium Phosphate Cement; Magnesium Oxide; Low-grade magnesium oxide; Phase Change Materials; Thermal conductivity

Corresponding Author: Mr. Alex Maldonado-Alameda, Ph.D Student

Corresponding Author's Institution: Universitat de Barcelona

First Author: Alex Maldonado-Alameda, Ph.D Student

Order of Authors: Alex Maldonado-Alameda, Ph.D Student; Ana Maria

Lacasta, Full Professor; Jessica Giro-Paloma, Associate Professor; Josep Maria Chimenos, Full Professor; Laia Haurie, Lecturer Professor; Joan Formosa, Lecturer Professor

Abstract: Magnesium Phosphate Cement (MPC) has become an essential reference for investigators seeking alternatives to the use of ordinary Portland Cement (OPC) in building sector because of its high environmental impact. The research group developed a MPC formulated with low-grade MgO (LG-MgO) by-product, which could be considered as a sustainable MPC (sust-MPC). This research focuses on the incorporation of different percentages of Microencapsulated Phase Change Materials (MPCM) into sust-MPC, due to their ability to reduce energy consumption of heating, ventilating, and air conditioning (HVAC) systems. The study consists of an exhaustive characterization of thermal sustainable MPC (TS-MPC) dosages which incorporate air-entraining additive (AEA) and MPCM to improve their thermal behaviour. Thus, TS-MPC would reduce the use of HVAC systems contributing to the decrease of $\mathrm{CO} 2$ emissions and increasing energy efficiency in buildings. Moreover, properties such as bulk density, porosity, thermal conductivity, modulus of elasticity, compressive strength, and flexural strength are analysed to evaluate the potential use of these cements as a part of a passive conditioning system. Results show the proper behaviour of these cements to reduce thermal oscillation in buildings. Experimental results demonstrated the relation between the amount of the MPCM and the AEA percentage as well as the thermal and mechanical properties of the TS-MPC due to their contribution to increase the porosity. Furthermore, it should be noted the increase of porosity and the reduction of thermal conductivity of the optimal formulation, which are 60\% higher and 50\% lower than the sust-MPC obtained without MPCM and additive, respectively. 
To Editor, Construction and Building Materials

Barcelona, $27^{\text {th }}$ July 2017

\section{Dear Editor}

We herewith submit the revised manuscript titled "Magnesium Phosphate Cements formulated with Low Grade Magnesium Oxide incorporating Phase Change Materials for thermal energy storage". The authors are Alex Maldonado Alameda, Ana Maria Lacasta Palacio, Jessica Giró Paloma, Josep Maria Chimenos Ribera, Laia Haurie Ibarra and Joan Formosa Mitjans. This work is not in submission and has not been published elsewhere. The authors confirm that any necessary permissions have been obtained.

The present manuscript represents completely new work with a major thermal and mechanical characterization component of new alternative cements based on industrial by-product. While there has been a large amount of published studies on Magnesium Phosphate Cement (MPC), the present research stands unique for its innovative contributions. It is well known the suitability of Phase Change Materials (PCM) for its use as a thermal comfort regulator in the field of building. The PCM contribution on the reduction of use of Heating, Ventilating and Air Conditioning (HVAC) systems are often considered. This manuscript aims to extend the applications of the MPC in the civil and building engineering, mixing them with PCM and air entraining additive (AEA) as admixtures. It is important to highlight that is the first time have been introduced PCM on these kind of cements, and have demonstrated its potential use as a thermal passive system.

The work strongly aligns with the Sustainable Construction topic areas, since is based on the elaboration of new ecofriendly cements obtained by means of an industrial byproduct. Therefore, in the present study is potentiate and promote some aspects such as recyclability and valorisation of residues of the industry.

We look forward to your response.

Yours faithfully,

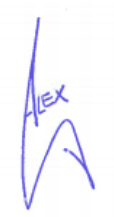

Alex Maldonado Alameda 


\title{
Title: Magnesium Phosphate Cements formulated with Low Grade Magnesium Oxide incorporating Phase Change Materials for thermal energy storage
}

\author{
Authors: A. Maldonado-Alameda, A.M. Lacasta, J. Giro-Paloma, J.M. Chimenos, \\ L. Haurie, J. Formosa
}

The responses of reviewer's comments and questions are presented below. Hopefully, we answered all the questions and clarified all issues. Enclosed, please find the revised manuscript.

\section{Answer to the comments of Reviewers}

\section{REVIEWER 1:}

The paper deals with an interesting subject. But, it is not well written. Further improvement is necessary.

We really appreciate this suggestion. Accordingly, the paper has been properly revised by linguistic services of University of Barcelona.

\section{* All commercial names are to be deleted.}

The authors of the article consider necessary the complete description of the raw materials used in the experiments for its possible reproducibility, and this includes the commercial names that appear in the article. Besides, there is an increasing use of commercial names published elsewhere. We kindly ask to Reviewer 1 to reconsider this point. Some examples of research articles providing commercial names are pointed below:

- Materials and Structures (2016) 49:225-239. Encapsulated Phase-Change Materials as additives in cementitious materials to promote thermal comfort in concrete constructions.

- Thermochimica Acta 553 (2013) 23-26. Study on differential scanning calorimetry analysis with two operation modes and organic and inorganic phase change material (PCM).

- Construction and Building Materials 112 (2016) 639-647. Mechanical and thermal characterization of concrete with incorporation of microencapsulated PCM for applications in thermally activated slabs.

- Construction and Building Materials 120 (2016) 408-417. Properties of cementitious mortar and concrete containing micro-encapsulated phase change materials.

\section{*All codes are to be listed in the references.}

The authors do not know if we have properly interpreted the word "codes". In any case, all references have been revised and those referring to the standards used in the lab tests have been added.

*We suggest to use "hours" instead of "h".

Thank you for the suggestion. Throughout the document is used hours instead $h$. 
*To estimate MOE by Eq. 3 is not correct, according to recent publications.

We really appreciate your suggestion, and we will take it into account for further studies.

On one hand, the authors conducted a new research concerning this comment. However, the following references use the same or similar equations in order to obtain the dynamic modulus of elasticity:

\section{Same equation:}

- Construction and Building Materials 146 (2017) 38-42. Bending strength and nondestructive evaluation of structural bamboo.

- J Indian Acad Wood Sci (June 2017) 14(1):18-23. Non-destructive estimation of modulus of elasticity of wood polymer composite.

\section{Similar equation:}

- Procedia Engineering 190 (2017) 111 - 117. The Acoustic Emission Parameters Obtained during Three-point Bending Test on Thermal-stressed Concrete Specimens.

- Construction and Building Materials 131 (2017) 31-38. Characterization of mortars with iron ore tailings using destructive and nondestructive tests.

On the other hand, the authors published some research articles by using the same equation:

- Construction and Building Materials 91 (2015) 150-157. Magnesium Phosphate Cements formulated with a low-grade $\mathrm{MgO}$ by-product: Physico-mechanical and durability aspects.

- Ceramics International42(2016)15049-15056. Magnesium phosphate cement formulated with low grade magnesium oxide with controlled porosity and low thermal conductivity as a function of admixture.

Furthermore, the authors are confident about the presented results due to the obtained values agreed with a deeply study related with this topic previously conducted and presented by the authors:

- Ceramics International 41(2015)12137-12146. Elastic modulus of a chemically bonded phosphate ceramic formulated with low-grade magnesium oxide determined by Nanoindentation.

However, we would like to emphasize that in the abovementioned reference, the W/S ratio used was different from the presented in the current manuscript under revision. Accordingly, the present values are lower than the obtained in the previous research.

*Figure 3 is too instructive. Not necessary.

Thank you for the suggestion. Figure 3 has been deleted.

*Missing information of the references, 15, 30, 35 .

The three references have been revised and the missing information has been included. 


\section{REVIEWER 2:}

The subject of the paper is quite interesting and it is very well written.

We are really thankful for your comment.

*Page 5. Please replace "needed" with "need".

Thank you for the suggestion. The word "needed" has been replaced by "need".

*Page 8. Sentence starting with "For each formulation..." should be revised.

- For each formulation, LG-MgO, MKP, and MPCM were added and weighed successively into the mixer, maintaining the same amount of solid $(3 \mathrm{~kg})$. On the other hand, tap water and the additive were mixed to be subsequently introduced into the mixer with the rest of the components.

has been replaced by:

All mixtures were prepared in the same way, i.e.: the solid reagents (LG-MgO, MKP, and MPCM) with a total mass of $3 \mathrm{~kg}$ were added and weighed successively into the mixer. Subsequently, the liquid reagents (tap kneading water and AEA) in order to proceed with mixture procedure were properly added.

- For each formulation, it has been obtained three prism shaped specimens of $40 \mathrm{x} 40 \mathrm{x}$ $160 \mathrm{~mm}$ and three plate shaped specimens of $150 \times 150 \times 35 \mathrm{~mm}$, which were conducted the tests shown in Error! Reference source not found..

has been replaced by:

Three prism shaped specimens of $40 \times 40 \times 160 \mathrm{~mm}$ and three plate shaped specimens of $150 \times 150 \times 35 \mathrm{~mm}$ were prepared for each formulation. Table 2 summarizes the conducted tests.

*Page 13. Sentence "...lower than the k-struvite..." should be revised.

- Hence, as the MPCM used in this research are mainly composed of heptadecane and octadecane [27], and their thermal conductivity is lower than the K-struvite [28-30], this addition leads to a decrease in the thermal conductivity of the TS-MPC mortars as it is shown in Error! Reference source not found.

has been replaced by:

The MPCM used in this research are mainly composed of heptadecane and octadecane. Therefore, MPCM presents a lower thermal conductivity than the k-struvite matrix (ref). Hence, the higher amount of MPCM in the mixture, the lower thermal conductivity of the obtained TS-MPC mortars, as it is shown in Fig. 3. 
*Figure foots of figures 4, 6 and 8 should specify differences among graphics a, b, c, etc., for better understanding.

Accordingly, we have revised and replaced the figure captions as it is shown below. Additionally, note that Figure 3 has been deleted by suggestion of another reviewer. Therefore, the figures 4,6 , and 8 have become figures 3,5 , and 7 .

\section{- Fig. 3}

Thermal conductivity of TS-MPC mortars at different temperatures as a function of weight ratio of MPCM and AEA added. (a) 0\% AEA, (b) 2\% AEA, and (c) 5\% AEA.

has been replaced by:

Thermal conductivity of TS-MPC mortars at $12^{\circ} \mathrm{C}, 20^{\circ} \mathrm{C}$ and $29^{\circ} \mathrm{C}$ as a function of weight ratio of MPCM added. (a) 0\% AEA, (b) 2\% AEA, and (c) 5\% AEA.

\section{- Fig. 5}

Thermal behaviour of TS-MPC mortars as a function of weight ratio of MPCM and AEA added. (a) $0 \%$ AEA, (b) 2\% AEA, and (c) 5\% AEA.

has been replaced by:

Thermal behaviour of TS-MPC mortars as a function of weight ratio of MPCM added. (a) $0 \%$ AEA, (b) $2 \%$ AEA, and (c) $5 \%$ AEA.

\section{- Fig. 7}

Modulus of elasticity of TS-MPC mortars as a function of weight ratio of MPCM and AEA added. (a) 7 days, (b) 21 days, and (c) 28 days of curing. has been replaced by:

Modulus of elasticity of TS-MPC mortars at different curing days as a function of the weight ratio of the MPCM and AEA added. (a) 7 days, (b) 21 days, and (c) 28 days.

*Page 18. What is the consequence of an increase in Modulus of Elasticity in TS-MPC mortars?

The increase of MOE in TS-MPC mortars implies an increase of stiffness and therefore leads to an improvement of the flexural strength. This should be considered for further potential applications, such as panels for developing thermal passive systems. 
*Pages 20 and 21. Obtained compressive and flexural strength values of TS-MPC should be compared with required values for construction materials.

According your interesting suggestion the following text has been added in the section of flexural strength:

"Flexural strength values comply with requirements for the cement flat sheets of European standard [37] excepting formulations containing MPCM and 5\% of AEA. Moreover, the values are comparable to other commercial products used for the same purpose."

In terms of compressive strength, there are no specific requirements for cement flat sheets, since it is not a structural material. Moreover, the technical sheets of the commercial products with the same purpose do not specify the compressive strength value. Consequently, the following text has been deleted in the section of compressive strength:

"Therefore, TS-MPC mortars as a porous material showed proper compressive strength values for the thermal passive system purposed." 


\section{Magnesium Phosphate Cements formulated with Low Grade} Magnesium Oxide incorporating Phase Change Materials for thermal energy storage

A. Maldonado-Alameda ${ }^{1,{ }^{*}}$, A.M. Lacasta ${ }^{2, \text { a }}$, J. Giro-Paloma ${ }^{1, \text { b }}$, J.M. Chimenos ${ }^{1, \mathrm{c}}$, L. Haurie $^{3, \mathrm{~d}}$, J. Formosa ${ }^{1, \mathrm{e}}$

$>$ Sust-MPC mortars by using an industrial by-product (Low Grade $\mathrm{MgO}$ ) were developed.

Sust-MPC incorporates microencapsulated PCM and air-entraining agent as admixtures.

Different dosages of Thermal and Sustainable MPC mortars (TS-MPC) were studied.

$>$ Physical, thermal and mechanical characterization for each TS-MPC was performed.

Thermal conductivity of the optimal TS-MPC mortar is 50\% lower than the sust-MPC. 


\title{
Magnesium Phosphate Cements formulated with Low Grade Magnesium Oxide incorporating Phase Change Materials for thermal energy storage
}

\author{
A. Maldonado-Alameda ${ }^{1, ~ *}$, A.M. Lacasta, a, J. Giro-Paloma ${ }^{1, \text { b }}$, J.M. Chimenos ${ }^{1, \mathrm{c}}$, L. Haurie ${ }^{3, \mathrm{~d}}$, \\ J. Formosa ${ }^{1, \mathrm{e}}$
${ }^{1}$ Departament de Ciència de Materials i Química Física, Universitat de Barcelona, C/Martí i Franquès, 1-11, 08028, Barcelona, Spain. Ph: +34-934037244, Fax: +34-934035438. e-mail: bjessicagiro@ub.edu; chimenos@ub.edu; ${ }^{\mathrm{c}}$ joanformosa@ub.edu \\ ${ }^{2}$ Departament de Física Aplicada, Universitat Politècnica de Catalunya, Av. Dr. Marañón 44-50, 08028 \\ Barcelona, Spain. e-mail: $\underline{\text { bana.maria.lacasta@upc.edu }}$ \\ ${ }^{3}$ Departament de Construccions Arquitectòniques II, Universitat Politècnica de Catalunya, Av. Dr. Marañón \\ 44-50, 08028 Barcelona, Spain. e-mail: daia.haurie@upc.edu
}

* Corresponding author: *alex.maldonado@ub.edu 


\begin{abstract}
Magnesium Phosphate Cement (MPC) has become an essential reference for investigators seeking alternatives to the use of Ordinary Portland Cement (OPC) in building sector because of its high environmental impact. The research group developed a MPC formulated with low-grade $\mathrm{MgO}$ (LG-MgO) by-product, which could be considered as a sustainable MPC (sust-MPC). This research focuses on the incorporation of different percentages of Microencapsulated Phase Change Materials (MPCM) into sust-MPC, due to their ability to reduce energy consumption of heating, ventilating, and air conditioning (HVAC) systems. The study consists of an exhaustive characterization of thermal sustainable MPC (TS-MPC) dosages which incorporate airentraining additive (AEA) and MPCM to improve their thermal behaviour. Thus, TSMPC would reduce the use of HVAC systems contributing to the decrease of $\mathrm{CO}_{2}$ emissions and increasing energy efficiency in buildings. Moreover, properties such as bulk density, porosity, thermal conductivity, modulus of elasticity, compressive strength, and flexural strength are analysed to evaluate the potential use of these cements as a part of a passive conditioning system. Results show the proper behaviour of these cements to reduce thermal oscillation in buildings. Experimental results demonstrated the relation between the amount of the MPCM and the AEA percentage as well as the thermal and mechanical properties of the TS-MPC due to their contribution to increase the porosity. Furthermore, it should be noted the increase of porosity and the reduction of thermal conductivity of the optimal formulation, which are $60 \%$ higher and $50 \%$ lower than the sust-MPC obtained without MPCM and additive, respectively.
\end{abstract}

Keywords: Magnesium Phosphate Cement, Magnesium Oxide, Low-grade magnesium oxide, Phase Change Materials, thermal conductivity. 


\section{Introduction}

The energy demand and the resource extractive activity are some of the environmental issues that have generated major interest in modern society [1,2]. Their consumption patterns, population growth, and economic development have led to an increase of energy consumption and waste generation, with the consequent appearance of problems such as increasing greenhouse gases (GHG), global warming, and depletion of natural resources.

In the framework of building, energy consumption is also very high and has a big impact in both economy and environment. Pérez-Lombard et al. [3] highlighted the global contribution from buildings towards energy consumption has raised up between $20 \%$ and $40 \%$, depending on the country or building use, outstripping other important sectors like industry and transportation. Among this quantity of consumed energy, around $50 \%$ is due to the use of heating, ventilating, and air conditioning (HVAC) systems to keep the thermal comfort and to improve the quality of life in buildings [3]. Moreover, in terms of material resources consumption, the building sector consumes around $24 \%$ of raw materials extracted from the lithosphere [4]. Thus, it also means that resource extractive activity caused by building material industry generates large amounts of $\mathrm{CO}_{2}$ and requires high quantity of energy. The ordinary Portland Cement (OPC), together with steel, is the most demanded material and, consequently, its environmental and energetic impact is an important threat to the Earth. The OPC production generates about 5 to $7 \%$ of $\mathrm{CO}_{2}$ global emissions [5] and consumes $2 \%$ of global energy demand [6]. Hence, those studies show the need to move towards a more sustainable economic and social model based on avoiding excessive and uncontrolled consumption of energy and available material resources. Besides, it is important to potentiate some aspects such as recyclability and the valorisation of waste generated by the industry, towards a circular economy. One of the available solutions from the 
materials engineering field is the design and use of eco-friendly building materials and systems, as the developed and investigated material in the present research work.

This research contributes into the development of eco-friendly building materials with new data on Magnesium Phosphate Cements (MPC) and Microencapsulated Phase Change Materials (MPCM). MPC is an acid-base cement that is part of the family of Chemically Bonded Phosphate Ceramics (CBPC). Due to its quick setting and early high strength, the main CBPC applications have been defined in the field of dentistry [7], stabilisation and encapsulation of hazardous and toxic wastes [8-10], and finally rapid repairing of roads, flooring, and concrete bridges [11,12]. However, in recent years, there is a tendency to expand their applications in other fields such as building. Apart from MPC properties, one reason of the great interest generated by this material is the ecological and environmental benefits that provides when compared with OPC [13]. The energy consumed to produce $1000 \mathrm{~kg}$ of OPC is approximately $5 \mathrm{GJ}$ and the amount of $\mathrm{CO}_{2}$ generated reaches $900 \mathrm{~kg}$ [14]. Nevertheless, in the study of Wagh [15] is showed that $\mathrm{CO}_{2}$ emissions generated by the MPC production are reduced up to $40 \%$ compared with OPC. This same study also highlights the process of producing MPC requires four times less amount of heat than the production of OPC. In addition, for the MPC formulation, it has been used a low-grade magnesium oxide (LG-MgO) obtained as a by-product from the calcination process of natural magnesite $\left(\mathrm{MgCO}_{3}\right)$ from the production of magnesia $(\mathrm{MgO})$. The MPC formulated through the use of LG-MgO has been successfully already obtained in other studies [16-18]. Hence, LG-MgO potentiates its sustainable and environmental criteria, valorising an industrial byproduct, and reducing natural resource extraction activities for the pure $\mathrm{MgO}$ production; on this manner, it is named sustainable MPC (sust-MPC) mortars [18].

The second material used in this study is MPCM which allows maintaining the thermal comfort in buildings because of its physical properties [19-23]. MPCM has 
been successfully incorporated in several construction materials such as lime, gypsum, and concrete, in order to reduce the energy consumption and $\mathrm{CO}_{2}$ emissions generated by the use of HVAC systems and to improve energy efficiency in buildings [19-23]. During the phase change process, Phase Change Materials (PCM) has the tendency to leak to the surface of the matrices in which they are contained. However, the leakage process can be avoided by an encapsulation process, producing MPCM. Therefore, the mixture between sust-MPC and MPCM will expand their range of applications, mainly for thermal purposes; consequently, in this research work, this kind of formulations has been named thermal sustainable MPC (TS-MPC).

The main goal of the present study is the evaluation of the potential use of an airentraining agent (AEA) and MPCM as admixtures on sust-MPC to improve their thermal behaviour, as well as to use this material as a passive conditioning system. Porosity and density of different dosages of TS-MPC have been evaluated to relate them to their thermal and mechanical properties. Furthermore, the influence of MPCM amount on the thermal conductivity and the thermal cycles behaviour of TS-MPC have been also studied.

\section{Experimental Details}

\subsection{Materials}

In the present study, a by-product of LG-MgO supplied by Magnesitas Navarras S.A. and a food grade monopotassium phosphate (MKP) supplied by J. Norken S.L. were used for the TS-MPC formulation. These two commercial products were characterized elsewhere by Formosa et. al. [16]. In addition, MPCM and AEA were used as admixtures.

The MPCM used was Micronal ${ }^{\circledR}$ DS 5008X from BASF company, which consist in a paraffin with a phase change temperature of $23^{\circ} \mathrm{C}$ and a melting enthalpy value of 135 
$\mathrm{kJ} \cdot \mathrm{kg}^{-1}$. The commercial AEA used was Centrament Air 207 from MC Bauchemie company.

\subsection{Samples Preparation}

The TS-MPC mortars were prepared by mixing LG-MgO, MKP, MPCM, tap kneading water, and the AEA according to the designed formulations as shown in Table 1. All mixtures were prepared in the same way, i.e.: the solid reagents (LG-MgO, MKP, and MPCM) with a total mass of $3 \mathrm{~kg}$ were added and weighed successively into the mixer. Subsequently, the liquid reagents (tap kneading water and AEA) in order to continue with mixture procedure were properly added. On the other hand, tap water and the additive were mixed to be subsequently introduced into the mixer with the rest of the components. The mixture was first mechanically stirred at low speed during $120 \mathrm{~s}$, and then at high speed during $60 \mathrm{~s}$, with $60 \mathrm{~s}$ as intermediate stop between both. Later, the mixture was poured into moulds and compacted in three steps by using a vibrating table, during $10 \mathrm{~s}$ for the first and second step and $5 \mathrm{~s}$ for the third one. Among each steps the vibration was stopped during $60 \mathrm{~s}$. The moulds were introduced into a humidity chamber at $25^{\circ} \mathrm{C} \pm 1{ }^{\circ} \mathrm{C}$ for 24 hours (relative humidity of $95 \% \pm 5 \%$ ). Finally, the specimens were unmoulded and cured at $20^{\circ} \mathrm{C} \pm 1{ }^{\circ} \mathrm{C}$ (relative humidity of $10 \% \pm 5$ $\%$ ) until constant weight, up to 7 days. Three prism shaped specimens of $40 \times 40 \times 160$ $\mathrm{mm}$ and three plate shaped specimens of $150 \times 150 \times 35 \mathrm{~mm}$ were prepared for each formulation. Table 2 summarizes the conducted tests.

Fig. 1 shows a flowsheet of the experimental measurements carried out. The plate shaped specimens were used for thermal conductivity, thermal cycling test, and bulk density and porosity measurements at the age of 7,8 , and 10 days, respectively. For the bulk density and the porosity, the specimens were cut in order to obtain three samples of 
$40 \times 75 \times 35 \mathrm{~mm}$. Furthermore, Modulus of Elasticity (MOE) and flexural and compressive strength were determined in the prism shaped specimens at the age of 721-28 and 28 days, respectively. The measurements were performed per triplicate for each formulation.

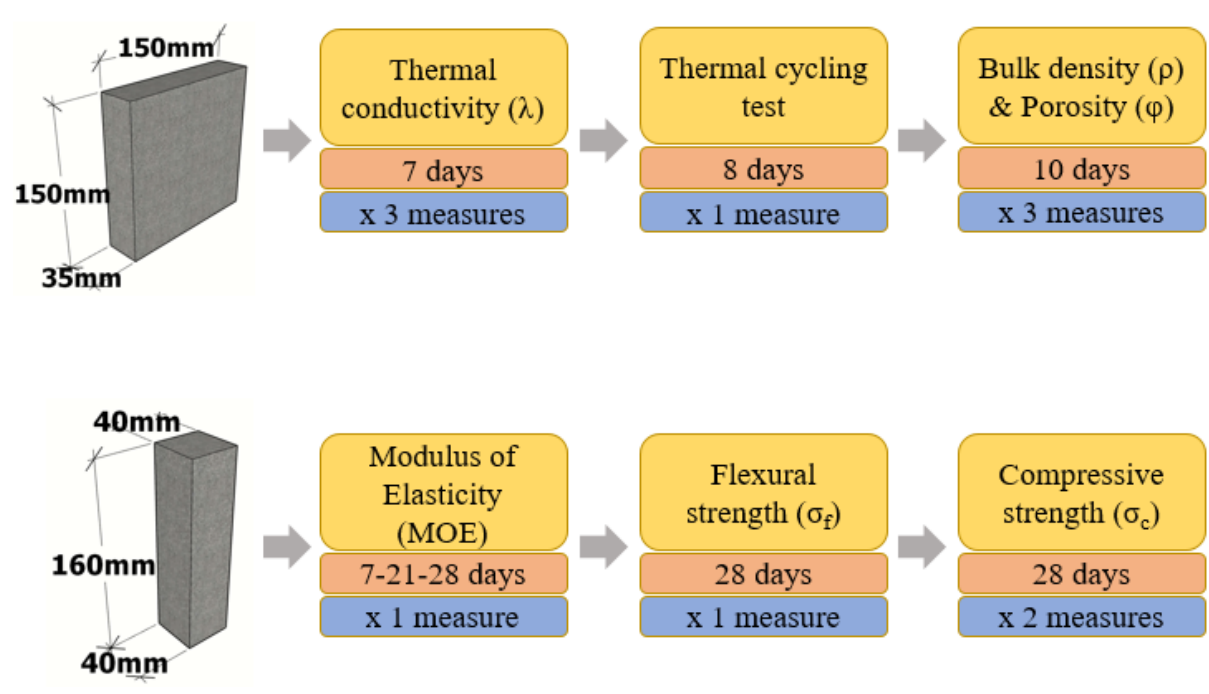

Fig. 1.

\subsection{Property measurements}

\subsubsection{Thermal conductivity}

The thermal conductivity was determined by using a Quickline-30 Thermal Properties analyser equipment. The analyser comes after a dynamic measurement method, based on the ASTM standard D5930 [24], using a surface probe placed in a planar area of the shaped plate sample. The used probe has a measuring range of 0.3 to $2.0 \mathrm{~W} \cdot \mathrm{m}^{-1} \cdot \mathrm{K}^{-1}$. For each plate, three measurements at different temperatures $\left(12^{\circ} \mathrm{C}\right.$, $20^{\circ} \mathrm{C}$, and $29^{\circ} \mathrm{C}$ ) were measured per triplicate at the age of 7 days, and then the average value of the thermal conductivity was determined. The selected values represent the upper and lower temperatures of the MPCM phase change, as well as at room temperature (around the phase change). 


\subsubsection{Thermal cycling test}

The shaped plate specimens were subjected to sudden temperature changes to evaluate the thermal inertia of the TS-MPC mortars. As shown in Fig. 2, the plate was first thermally stabilized in a fridge at $12^{\circ} \mathrm{C}$ during 24 hours, and then introduced into an oven at $40^{\circ} \mathrm{C}$. After 3 hours, the sample was once again introduced into the fridge during 3 more hours. This cycling procedure aims to simulate real environmental variations during the day and night (e.g. Mediterranean climate). The surface and internal temperature data of the sample were collected during this complete cycle, by using thermocouples and a thermal data-logger. Thermal cycling tests were performed one day after measuring the thermal conductivity (i.e. at the age of 8 days).

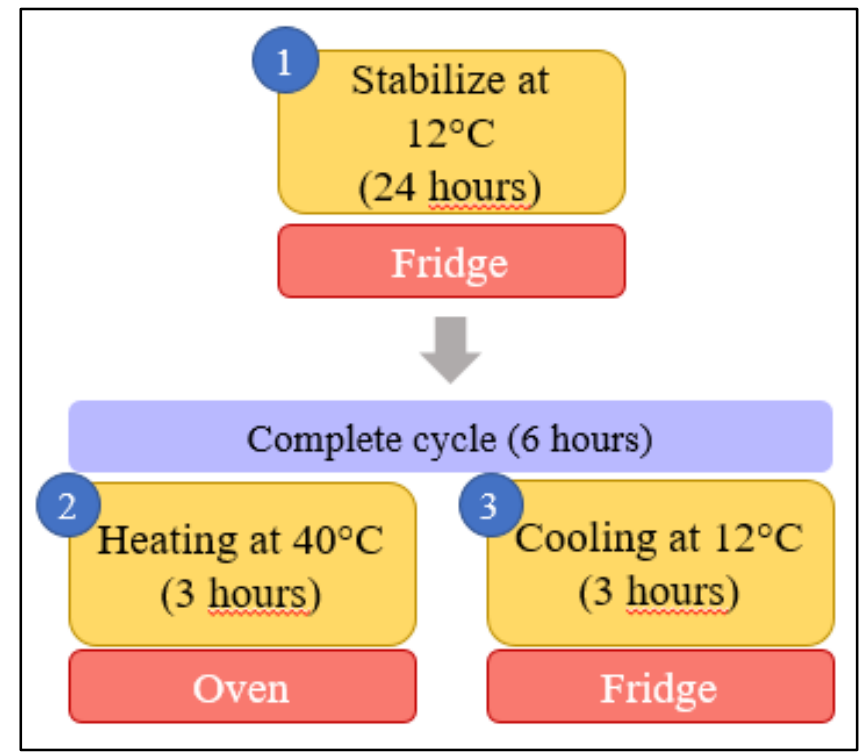

Fig. 2.

\subsubsection{Bulk density and porosity}

Specimens used for thermal cycling tests were previously conditioned to determine bulk density $(\rho)$ and porosity $(\phi)$ (cut and dried at $40^{\circ} \mathrm{C}$ during 24 hours). Hence, both properties were studied for a better understanding of thermal and mechanical properties 
of the TS-MPC mortars (i.e. at the age of 10 days). The values were determined at room temperature following the Archimedes principle, as Eq. (1) and Eq. (2) show:

$$
\begin{aligned}
\rho\left(\frac{g}{\mathrm{~cm}^{3}}\right) & =\frac{\text { Dried mass }}{\text { Hydrostatic mass }} \\
\phi(\%) & =\frac{\text { Saturated mass }- \text { Dried mass }}{\text { Hydrostatic mass }} \cdot 100
\end{aligned}
$$

\subsubsection{Modulus of Elasticity, flexural and compressive strength}

MOE measurements were carried out through a non-destructive test following the standard UNE-EN 12504-4 [25]. Tests were carried out by means of acoustic waves' application in the longitudinal direction of shaped-prism specimens. Then, the wave delay time along the length of each specimen was measured with a C368 Matest equipment. The results from tests were obtained assuming that the expressions used in the estimation of MOE were valid at both isotropic and homogeneous media [17]. MOE of each formulation was determined with the wave delay time value according to Eq. (3) and Eq. (4):

$$
\begin{aligned}
M O E & =\rho \cdot V^{2} \\
V & =2 \cdot L \cdot f
\end{aligned}
$$

where $\rho\left(\mathrm{kg} \cdot \mathrm{m}^{-3}\right)$ is the density, $V\left(\mathrm{~m} \cdot \mathrm{s}^{-1}\right)$ is the longitudinal passage velocity, $L(\mathrm{~m})$ is the prism length, and $f(\mathrm{~Hz})$ is the longitudinal vibration frequency.

The compressive $\left(\sigma_{\mathrm{c}}\right)$ and flexural strength $\left(\sigma_{\mathrm{f}}\right)$ tests at 28 curing days of the TSMPC mortars were determined according to UNE-EN 196-1 [26] using an Incotecnic MULTI-R1 equipment. A progressive load until fracture was applied in both cases, with a loading rate of $240 \mathrm{~kg} \cdot \mathrm{s}^{-1}$ and $5 \mathrm{~kg} \cdot \mathrm{s}^{-1}$ for compressive and flexural strength, respectively. Regarding $\sigma_{\mathrm{f}}$ test, it was first measured the maximum applied load for each of the three prism shaped specimens and then $\sigma_{\mathrm{f}}$ was determined. In the case of $\sigma_{\mathrm{c}}$ test, 
each of the two halves obtained in the flexural test was used; hence, 6 values of maximum applied load were determined.

\subsubsection{Microstructure and morphology}

The microstructural and morphological investigation of TS-MPC mortars were carried out with a scanning electron microscope (SEM) FEI Quanta 200. The micrographs were collected at voltages of $20 \mathrm{kV}$ and working distance of $10 \mathrm{~mm}$. The preparation of the samples for SEM observation consisted of cutting the plate shaped specimens after thermal cycling tests. Consequently, a diamond disc cutter at low velocity $\left(140 \mathrm{~min}^{-1}\right)$ has been used to avoid the degradation of the microcapsules. Two planar samples of one $\mathrm{cm}^{2}$ in size were obtained from each formulation. The samples were coated with graphite due to the non-conductive nature of the TS-MPC mortars.

\section{Results and discussion}

\subsection{Thermal properties}

\subsubsection{Thermal conductivity}

Fig. 3 depicts the thermal conductivity trend of TS-MPC mortars, measured at $12^{\circ} \mathrm{C}$, $20^{\circ} \mathrm{C}$, and $29^{\circ} \mathrm{C}$, as a function of MPCM and AEA added. As expected, the results show an inverse relation between the added admixtures amount and the thermal conductivity obtained. As expected, in the sust-MPC (0\% MPCM) thermal conductivity increases as increasing the temperature. The MPCM used in this research are mainly composed of heptadecane and octadecane [27]. Therefore, MPCM presents a lower thermal conductivity than the k-struvite [28-30]. Hence, the higher amount of MPCM in the mixture, the lower thermal conductivity of the obtained TS-MPC mortars, as it is shown in Fig. 3. Regarding thermal conductivity at $29^{\circ} \mathrm{C}$ in TS-MPC mortars, its value was lower than those at $20^{\circ} \mathrm{C}$, due to liquids' thermal conductivity is lower than solids. 


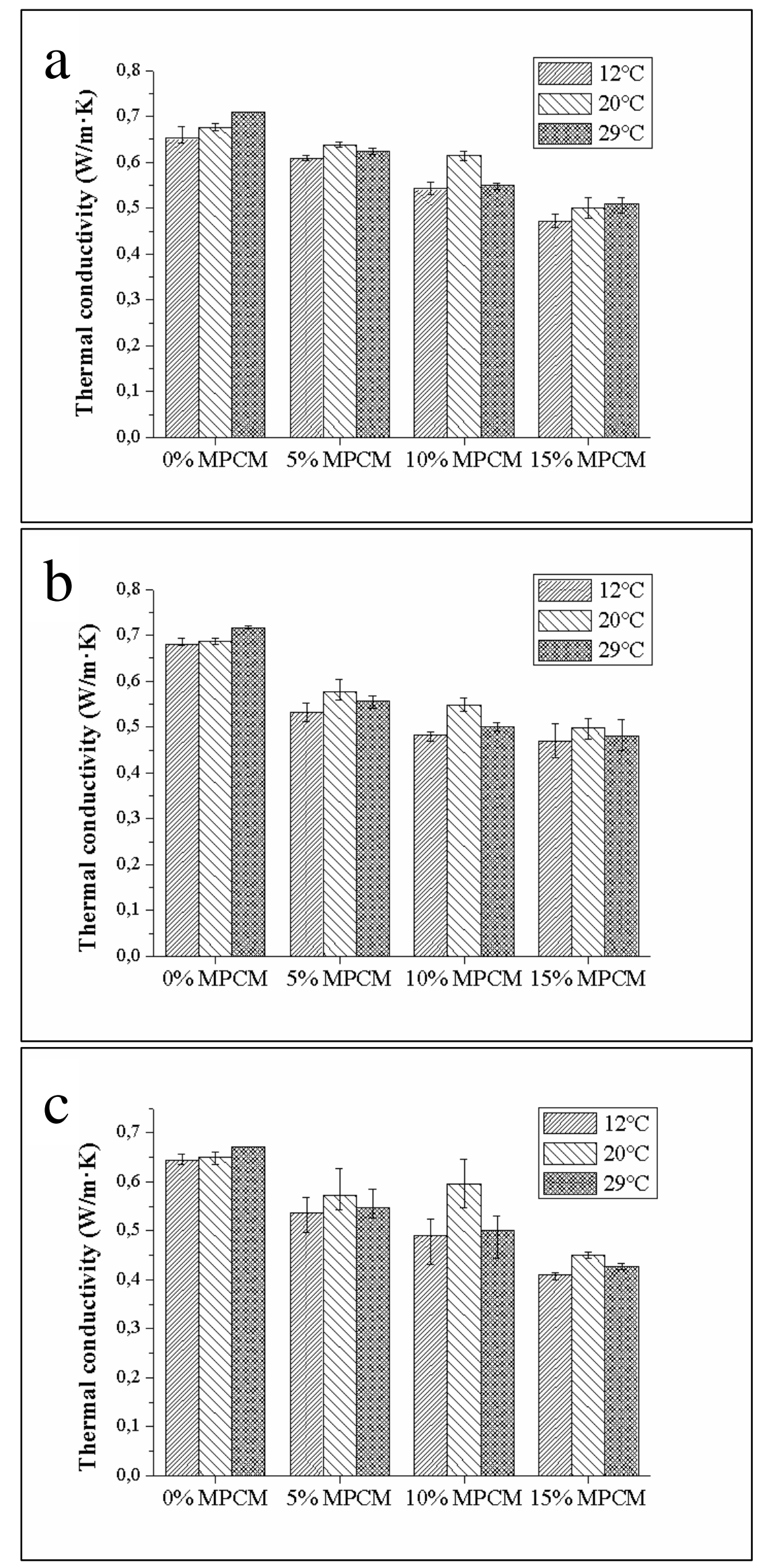

Fig. 3. 
As it can be observed in Fig. 4, an increase of the porosity produced by increasing the amount of admixtures has a positive effect on the thermal conductivity decrease of TS-MPC mortars because air into pores hinder the heat transfer.

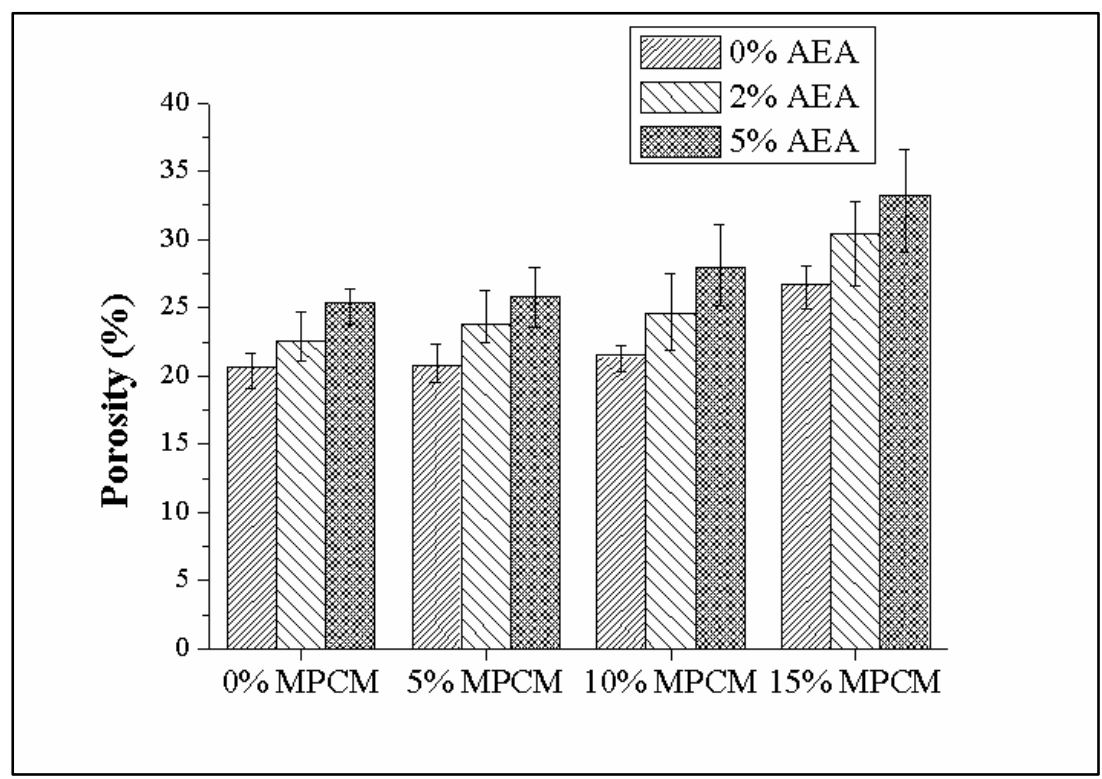

Fig. 4.

\subsubsection{Thermal cycling test}

Through these tests a greater understanding of the relationship between the admixtures amount and the thermal inertia were obtained. Fig. 5 depicts the room temperature (RT) where was the plate and the internal temperature of shaped plate specimen during a complete heating-cooling cycle for each formulation. Regarding the thermal inertia of the TS-MPC mortars, the effect of MPCM and AEA can be analysed by observing the shape of the obtained curves. In the first case, the increase of MPCM quantity involves an increase of latent heat storage capability, which means a greater thermal inertia on the TS-MPC mortars. This phenomenon is specially observed when the mortar temperature is around $23^{\circ} \mathrm{C}$ (e.g. Fig. 5c). At this temperature takes place the solid-liquid phase change of the paraffin contained in the microcapsules (MPCM) [31]. 
After approximately one hour of the heating and cooling cycle, it can be observed that there is a substantial difference in temperature among mortars containing and not containing MPCM. On the other hand, the increase on the amount of MPCM and AEA leads to an increase in the porosity, which involves in turn a decrease of the thermal diffusivity. This behaviour suggests that the porosity counteracts the effect of increasing the thermal inertia produced by increasing the amount of MPCM.
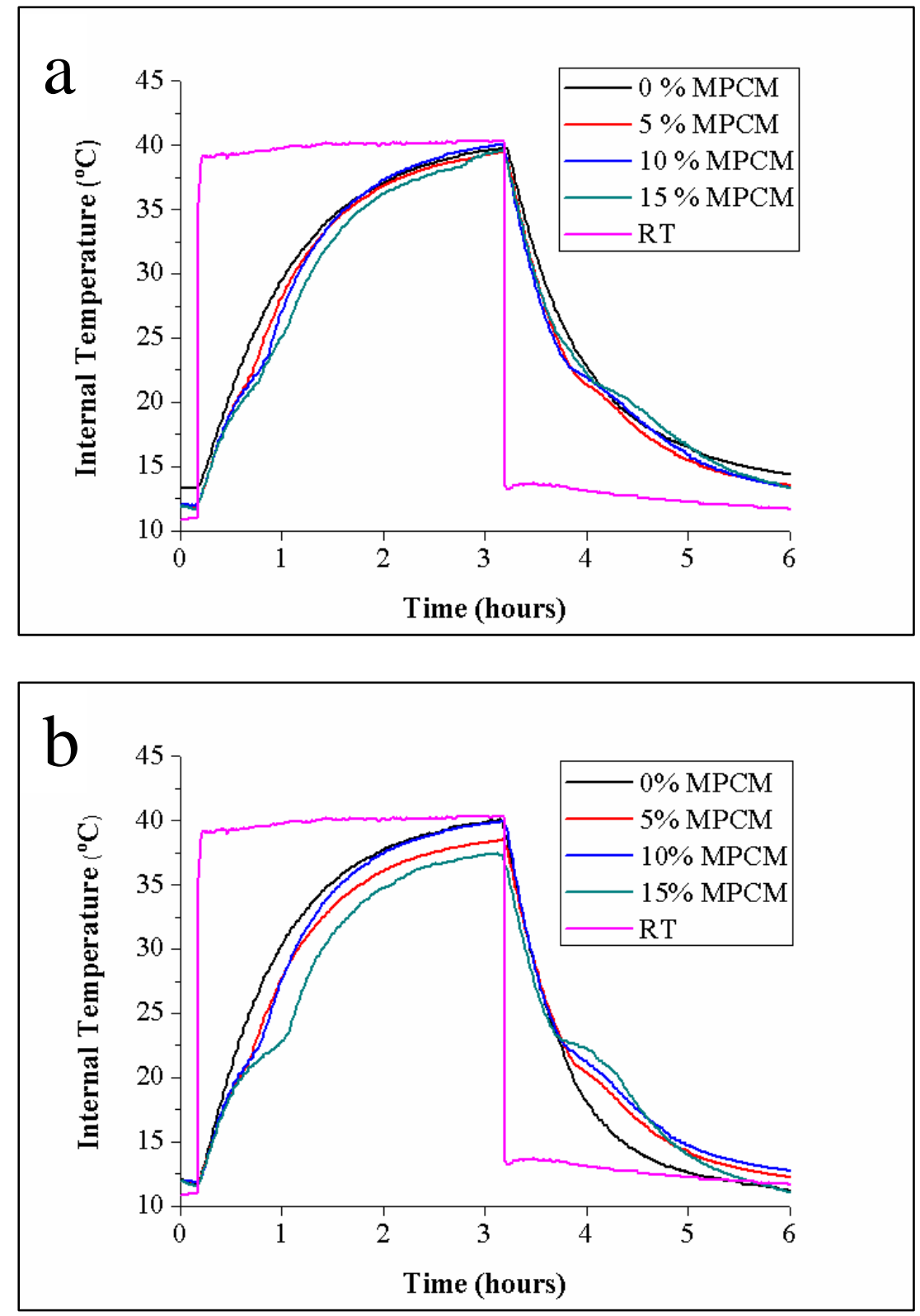


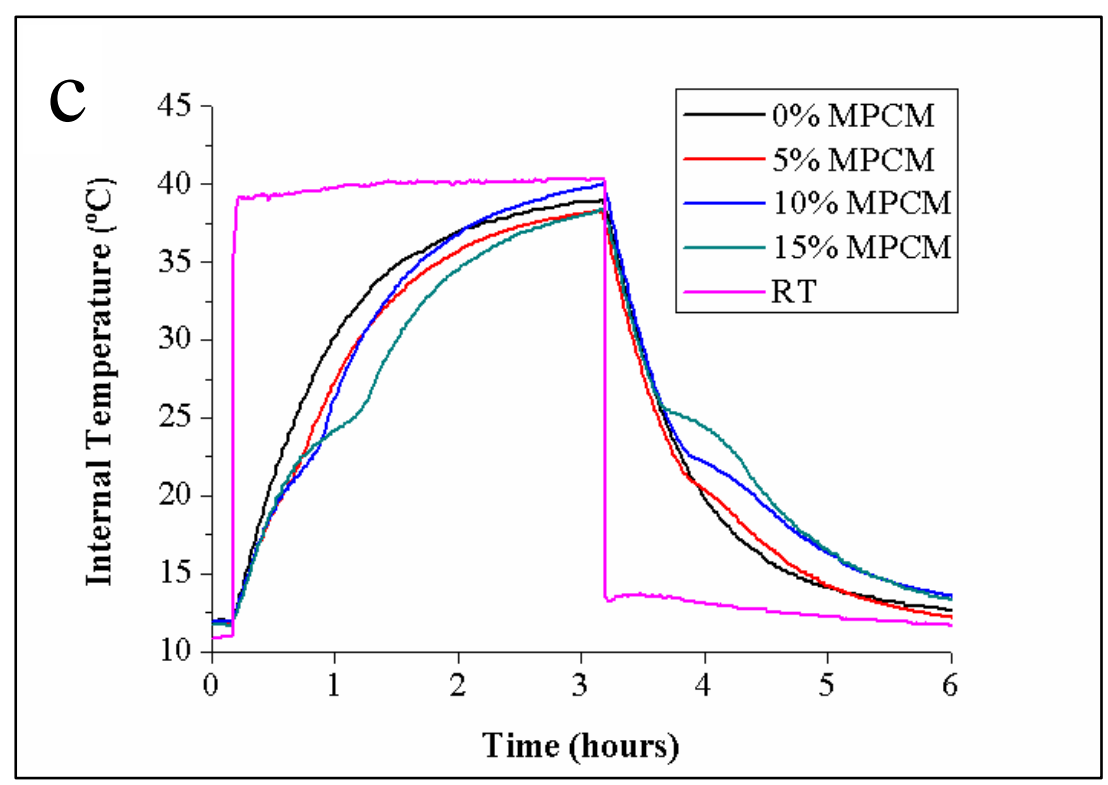

Fig. 5.

\subsection{Bulk density and porosity}

The bulk density and porosity were determined to analyse the thermal and mechanical behaviour of the TS-MPC mortars because these properties are strongly linked. As illustrated in Fig. 4 and Fig. 6, the effect of increasing the amount of admixtures added in the sust-MPC mortars leads to a variation on the values of these two above mentioned properties. First, the low MPCM density [32,33] compared to the MPC mortars contributes to the decrease of the material bulk density. On the other hand, increasing the amount of AEA causes an increase of porosity, as depicted in Fig. 4, which in turn helps to decrease the bulk density. Furthermore, the trend observed in Fig. 4 not only demonstrates that AEA satisfies its main objective of increase porosity but also validates that MPCM also contributes. 


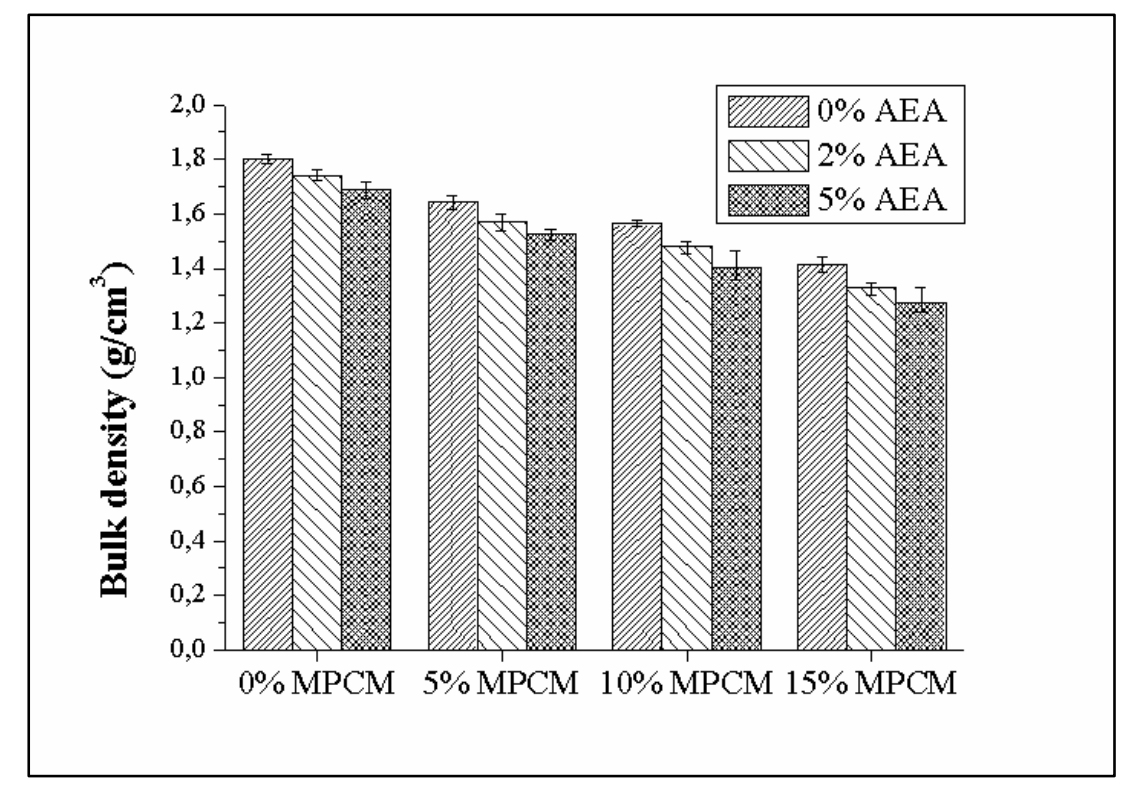

Fig. 6.

\subsection{Mechanical properties}

\subsubsection{Modulus of Elasticity}

MOE of the mortars after 7, 21, and 28 days are shown in Fig. 7. Results are related to porosity and bulk density of TS-MPC shown in Fig. 4 and Fig. 6, respectively. An increase of the porosity leads to a decrease of bulk density, which involves less compactness of TS-MPC mortar and lower MOE. When compactness decreases, the ultrasound wave propagation through the material decreases as well as the stiffness [17]. Likewise, the results reveal that MOE increases when the curing time increases. This phenomenon is due to the crystallization, which takes place on the cement matrix of mortars [34-36]. The crystallization effect is more noticeable on formulations without AEA because their porosity is lower as well as a higher densification of the mortar is allowed. Finally, it is important to highlight the effect of MPCM addition, because a higher quantity leads to a lower MOE value. This behaviour is due to the lower MOE value of the microcapsules [27] compared with the K-struvite cementitious matrix. 


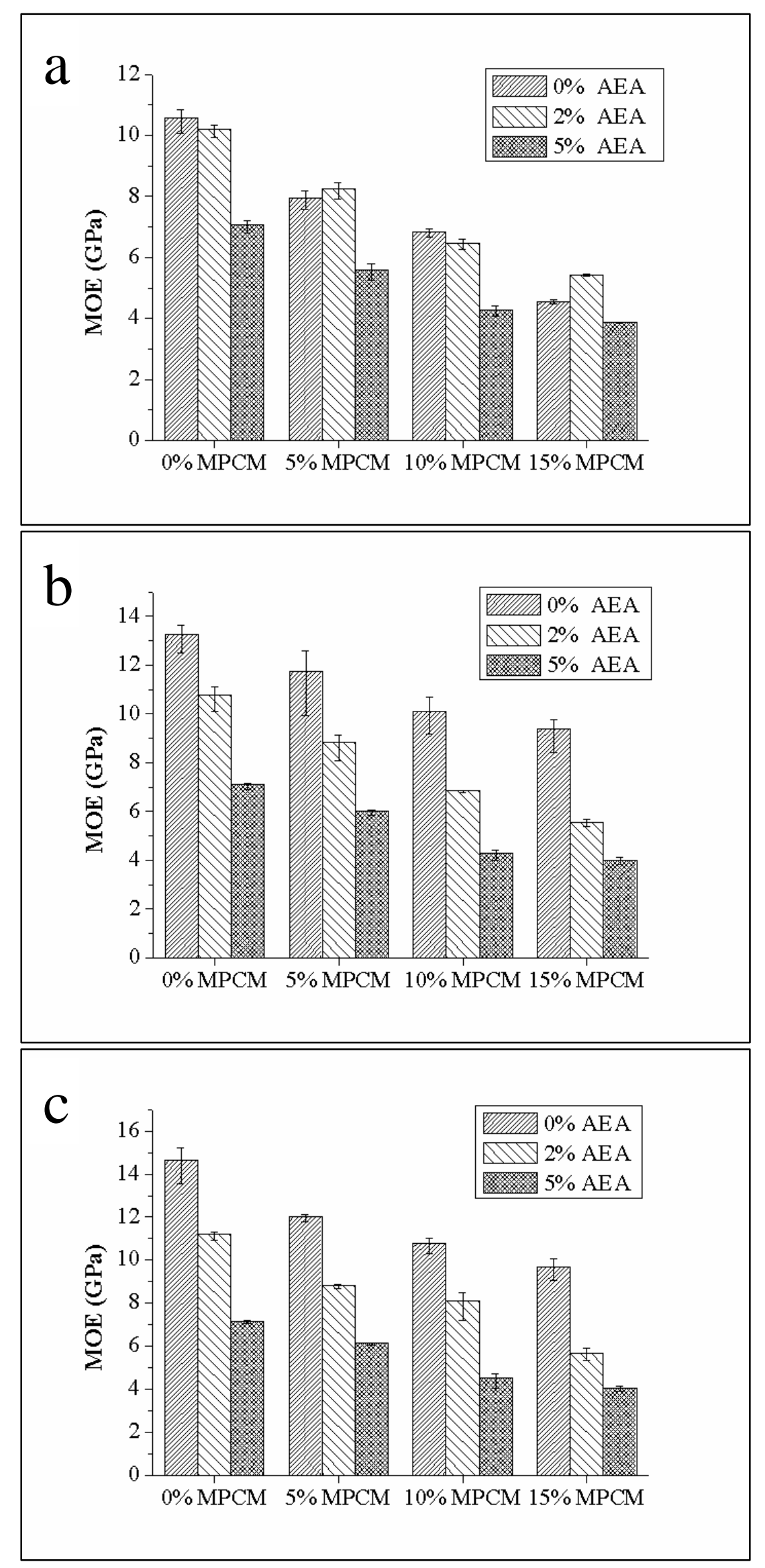

Fig. 7. 


\subsubsection{Flexural strength}

The flexural strength of TS-MPC mortars was measured after 28 days, and the results are illustrated in Fig. 8. As it was expected, the addition of admixtures leads to a decrease in the mechanical properties. This trend is because of the mortars porosity effect on the admixtures. The increase of porosity caused by the MPCM and the AEA involves a decrease in flexural strength. The flexural strength remains practically constant for mortars without AEA, because the microcapsules decrease the stiffness, as it was reported in the previous section, and reduce the negative effect of the porosity generated for the AEA addition (see Fig. 4). Flexural strength values comply with requirements for the cement flat sheets of European standard [37] excepting formulations containing PCM and 5\% of AEA. Moreover, the values are comparable to other commercial products used for the same purpose.

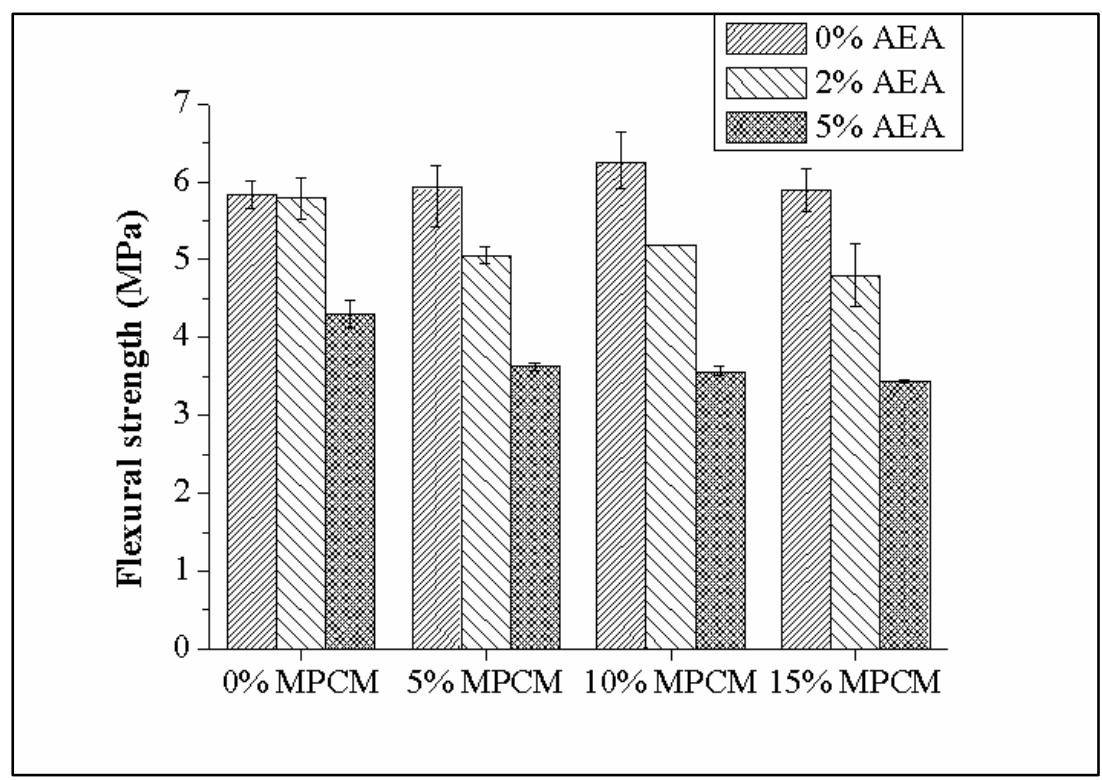

Fig. 8.

\subsubsection{Compressive strength}


The compressive strength of the TS-MPC mortars measured after 28 days is illustrated in Fig. 9. As for the flexural strength, the addition of admixtures decreases the compressive strength, although according to the results these values can be useful for certain building applications. The compressive mechanism promotes the closing of cavities and a reduction on the speed of cracks propagation $[38,39]$.

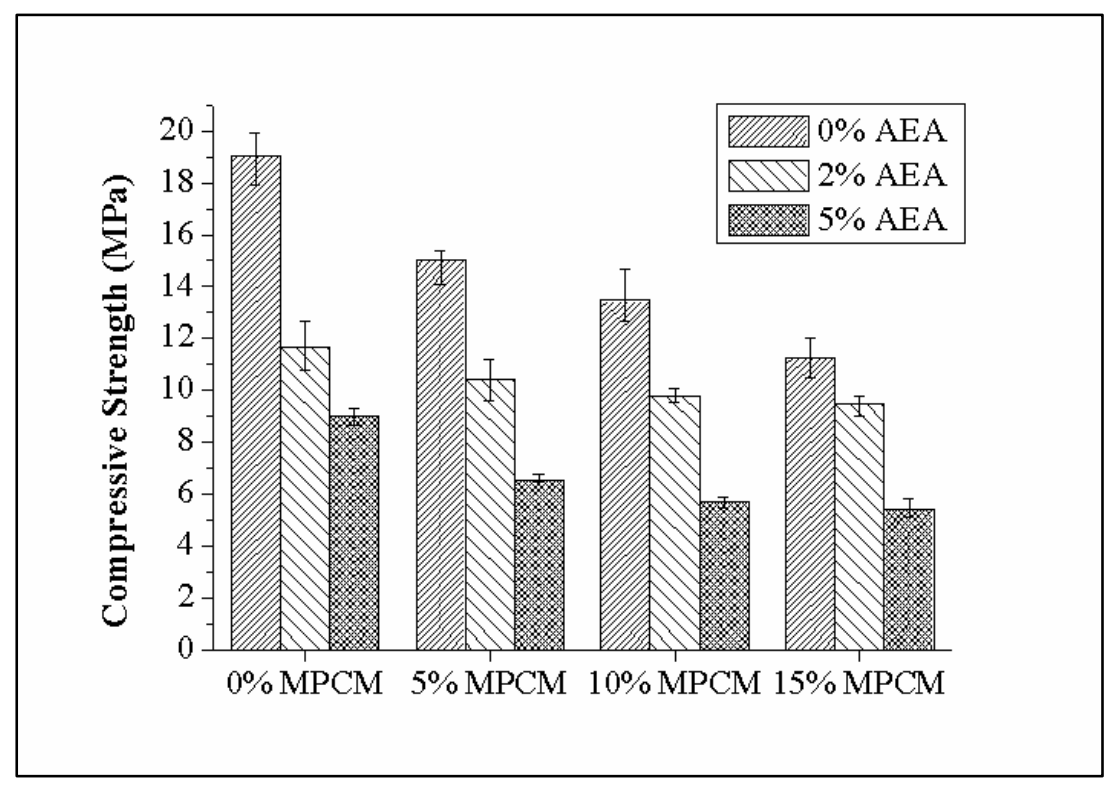

Fig. 9.

\subsection{Morphology and composition}

The micrograph of the TS-MPC mortar, by means of SEM in backscattering mode, is shown in Fig. 10. As can be observed, the mortar is mainly formed by a cementitious matrix with the typical morphology of K-struvite (sust-MPC matrix). The microstructure composition of TS-MPC has been exhaustively studied elsewhere $[17,18]$. The presence of inert phases, such as carbonates and unreacted LG-MgO cores, act as fillers improving the mechanical behaviour of the mortar [17]. Finally, it should be noted that MPCM (black spherical zones) are proper embedded into the cementitious 
matrix, suggesting an appropriate cohesion and spatial homogeneity between the binder matrix and the MPCM added.

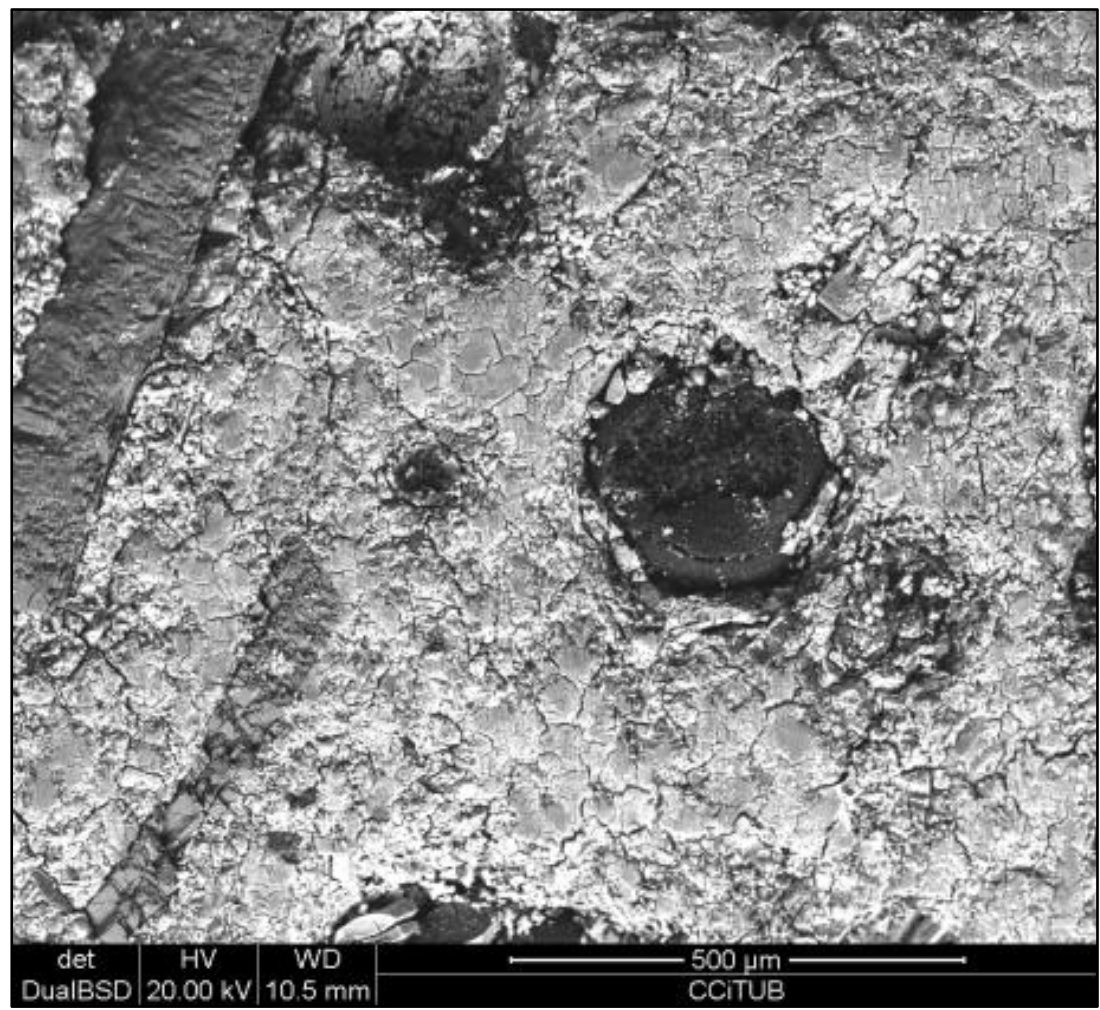

Fig. 10 .

\section{Conclusions}

In this paper, an experimental investigation of sust-MPC mortars containing MPCM and AEA are presented. Results corroborate that it is possible to formulate sust-MPC with magnesium by-product incorporating an AEA and MPCM as admixture improving thermal properties for the energy consumption reduction in HVAC systems. This implies the revalorization of the by-product and allows promoting aspects such as sustainability and reduction of $\mathrm{CO}_{2}$ emissions due to the reduction of mining activity of pure $\mathrm{MgO}$.

Moreover, the study of bulk density and porosity allows determining the influence of the admixtures content in the TS-MPC mortars. An increase of the amounts of admixtures involves lower bulk density and higher porosity. In addition, the increase in 
content of MPCM and AEA reduces the thermal conductivity. Furthermore, the heat storage capacity of the TS-MPC mortars is significantly improved with the addition of MPCM. Besides, MOE evaluation of each formulation at different ages shows that the value is increased over time, due to the densification and crystallization of K-struvite cementitious matrix. The content variation of MPCM and AEA in the TS-MPC dosages has a negative effect on the mechanical properties, which shows a downward trend when admixtures amounts increase. This behaviour is attributed to an increase of porosity and a density decrease.

Regarding the microstructure analysis of TS-MPC, the main product obtained is Kstruvite, which acts as a binder containing inert phases as fillers. It can also be observed that MPCM were well embedded into the binder matrix.

Finally, it is important to highlight that the present study sheds light on the formulating feasibility of a new eco-friendly mortar, named as the TS-MPC. Moreover, the TS-MPC thermal behaviour suggests the possibility to be used it as a part of a thermal passive conditioning system in order to reduce the consumption of HVAC systems. The future authors' investigations will be focused on the study of stability of MPCM on sust-MPC matrix.

\section{Acknowledgements}

The authors would like to thank Magnesitas Navarras, S.A. for supporting and financing this research project. We also want to thank J. Norken, S.L. for supplying monopotassium phosphate (MKP). The work is partially funded by the Spanish government ENE2015-64117-C5-2-R. The research leading to these results has received funding from the European Union's Seventh Framework Programme (FP7/2007-2013) under grant agreement $n^{\circ}$ PIRSES-GA-2013-610692 (INNOSTORAGE). The authors would like to thank the Catalan Government for the quality accreditation given to their 
research groups DIOPMA (2014 SGR 1543) and GICITED (2014 SGR 1298). Alex Maldonado-Alameda is grateful to the Government of Catalonia for the research grant (FI-DGR 2017).

\section{Bibliography}

[1] S. Kadoshin, T. Nishiyama, T. Ito, The trend in current and near future energy consumption from a statistical perspective, Appl. Energy. 67 (2000) 407-417. doi:10.1016/S0306-2619(00)00033-7.

[2] A. Behrens, S. Giljum, J. Kovanda, S. Niza, The material basis of the global economy. Worldwide patterns of natural resource extraction and their implications for sustainable resource use policies, Ecol. Econ. 64 (2007) 444453. doi:10.1016/j.ecolecon.2007.02.034.

[3] L. Pérez-Lombard, J. Ortiz, C. Pout, A review on buildings energy consumption information, Energy $\quad$ Build. $40 \quad$ (2008) 394-398. doi:10.1016/j.enbuild.2007.03.007.

[4] I. Zabalza Bribián, A. Valero Capilla, A. Aranda Usón, Life cycle assessment of building materials: Comparative analysis of energy and environmental impacts and evaluation of the eco-efficiency improvement potential, Build. Environ. 46 (2011) 1133-1140. doi:10.1016/j.buildenv.2010.12.002.

[5] B.C. McLellan, R.P. Williams, J. Lay, A. Van Riessen, G.D. Corder, Costs and carbon emissions for geopolymer pastes in comparison to ordinary portland cement, J. Clean. Prod. 19 (2011) 1080-1090. doi:10.1016/j.jclepro.2011.02.010.

[6] I.A. Chen, Synthesis of Portland Cement and Calcium Sulfoaluminate-Belite Cement for Sustainable Development and Performance, PCA R\&D Ser. No. SN3130. (2009) 1-216. 
[7] G. Mestres, M.P. Ginebra, Novel magnesium phosphate cements with high early strength and antibacterial properties, Acta Biomater. 7 (2011) 1853-1861. doi:10.1016/j.actbio.2010.12.008.

[8] A.S. Wagh, R. Strain, S.Y. Jeong, D. Reed, T. Krause, D. Singh, Stabilization of Rocky Flats Pu-contaminated ash within chemically bonded phosphate ceramics, J. Nucl. Mater. 265 (1999) 295-307. doi:10.1016/S0022-3115(98)00650-3.

[9] P. Randall, S. Chattopadhyay, Advances in encapsulation technologies for the management of mercury-contaminated hazardous wastes, J. Hazard. Mater. 114 (2004) 211-223. doi:10.1016/j.jhazmat.2004.08.010.

[10] I. Buj, J. Torras, M. Rovira, J. de Pablo, Leaching behaviour of magnesium phosphate cements containing high quantities of heavy metals, J. Hazard. Mater. 175 (2010) 789-794. doi:10.1016/j.jhazmat.2009.10.077.

[11] Q. Yang, X. Wu, Factors influencing properties of phosphate cement-based binder for rapid repair of concrete, Cem. Concr. Res. 29 (1999) 389-396. doi:10.1016/S0008-8846(98)00230-0.

[12] F. Qiao, C.K. Chau, Z. Li, Property evaluation of magnesium phosphate cement mortar as patch repair material, Constr. Build. Mater. 24 (2010) 695-700. doi:10.1016/j.conbuildmat.2009.10.039.

[13] D. Zheng, T. Ji, C. Wang, C. Sun, X. Lin, K. Muhammed, A. Hossain, Effect of the combination of fly ash and silica fume on water resistance of Magnesium Potassium Phosphate Cement, Constr. Build. Mater. 106 (2016) 415-421. doi:http://dx.doi.org/10.1016/j.conbuildmat.2015.12.085.

[14] C.K. Chau, F. Qiao, Z. Li, Microstructure of magnesium potassium phosphate cement, Constr. Build. Mater. $25 \quad$ (2011) 2911-2917. doi:10.1016/j.conbuildmat.2010.12.035.

[15] A.S. Wagh, Chemically Bonded Phosphate Ceramic Matrix Composites, Chem. 
Bond. Phosphate Ceram. (2004) 157-176. doi:10.1016/B978-0080445052/50018-1.

[16] J. Formosa, M.A. Aranda, J.M. Chimenos, J.R. Rosell, A.I. Fernández, O. Ginés, Cerámica y Vidrio Cementos químicos formulados con subproductos de óxido de magnesio, 297 (2008) 293-297.

[17] J. Formosa, A.M. Lacasta, A. Navarro, R. Del Valle-Zermeño, M. Niubó, J.R. Rosell, J.M. Chimenos, Magnesium Phosphate Cements formulated with a lowgrade $\mathrm{MgO}$ by-product: Physico-mechanical and durability aspects, Constr. Build. Mater. 91 (2015) 150-157. doi:10.1016/j.conbuildmat.2015.05.071.

[18] M. Niubó, J. Formosa, A. Maldonado-Alameda, R. del Valle-Zermeño, J.M. Chimenos, Magnesium phosphate cement formulated with low grade magnesium oxide with controlled porosity and low thermal conductivity as a function of admixture, Ceram. Int. $\quad 42 \quad$ (2016) 15049-15056. doi:10.1016/j.ceramint.2016.06.159.

[19] A.M. Khudhair, M.M. Farid, A review on energy conservation in building applications with thermal storage by latent heat using phase change materials, Energy Convers. Manag. 45 (2004) 263-275. doi:10.1016/S01968904(03)00131-6.

[20] L.F. Cabeza, C. Castellón, M. Nogués, M. Medrano, R. Leppers, O. Zubillaga, Use of microencapsulated PCM in concrete walls for energy savings, Energy Build. 39 (2007) 113-119. doi:10.1016/j.enbuild.2006.03.030.

[21] V.V. Tyagi, D. Buddhi, PCM thermal storage in buildings: A state of art, Renew. Sustain. Energy Rev. 11 (2007) 1146-1166. doi:10.1016/j.rser.2005.10.002.

[22] D. Zhou, C.Y. Zhao, Y. Tian, Review on thermal energy storage with phase change materials (PCMs) in building applications, Appl. Energy. 92 (2012) 593605. doi:10.1016/j.apenergy.2011.08.025. 
[23] T.-C.C. Ling, C.-S.S. Poon, Use of phase change materials for thermal energy storage in concrete: An overview, Constr. Build. Mater. 46 (2013) 55-62. doi:10.1016/j.conbuildmat.2013.04.031.

[24] D. ASTM, 5930--01. Standard test method for thermal conductivity of plastics by means of a transient line-source technique, in: Am. Soc. Test. Mater., 2002.

[25] A.E. de Normalización y Certificación, UNE-EN 12504-4: ensayos de hormigón en estructuras. Determinación de la velocidad de los impulsos ultrasónicos, 2006. https://books.google.es/books?id=XhUvcgAACAAJ.

[26] A.E. de Normalización y Certificación, UNE-EN 196-1: métodos de ensayo de cementos. Parte 1, Determinación de resistencias mecánicas, AENOR, 2005. https://books.google.es/books?id=7kRJnQEACAAJ.

[27] J. Giro-Paloma, R. Al-Shannaq, A.I. Fernández, M.M. Farid, Preparation and Characterization of Microencapsulated Phase Change Materials for Use in Building Applications, Materials (Basel). 9(1) (2016) 1-13. doi:10.3390/ma9010011.

[28] N.B. Vargaftik, Handbook of thermal conductivity of liquids and gases, CRC press, 1993.

[29] C. Vélez, M. Khayet, J.M. Ortiz De Zárate, Temperature-dependent thermal properties of solid/liquid phase change even-numbered n-alkanes: N-Hexadecane, n-octadecane and n-eicosane, Appl. Energy. $143 \quad$ (2015) 383-394. doi:10.1016/j.apenergy.2015.01.054.

[30] C. Vélez, J.M. Ortiz De Zárate, M. Khayet, Thermal properties of n-pentadecane, n-heptadecane and n-nonadecane in the solid/liquid phase change region, Int. J. Therm. Sci. 94 (2015) 139-146. doi:10.1016/j.ijthermalsci.2015.03.001.

[31] M. Hunger, A.G. Entrop, I. Mandilaras, H.J.H. Brouwers, M. Founti, The behavior of self-compacting concrete containing micro-encapsulated Phase 
Change Materials, Cem. Concr. Compos. 31 (2009) 731-743. doi:10.1016/j.cemconcomp.2009.08.002.

[32] A.G. Entrop, H.J.H. Brouwers, A.H.M.E. Reinders, Experimental research on the use of micro-encapsulated Phase Change Materials to store solar energy in concrete floors and to save energy in Dutch houses, Sol. Energy. 85 (2011) 1007-1020. doi:10.1016/j.solener.2011.02.017.

[33] G. Sant, N. Neithalath, Compositions comprising phase change material and concrete and uses thereof, US20150007752 A1, 2013. https://www.google.com/patents/US20150007752.

[34] A. Viani, K. Sotiriadis, P. Šašek, M.S. Appavou, Evolution of microstructure and performance in magnesium potassium phosphate ceramics: Role of sintering temperature of $\mathrm{MgO}$ powder, Ceram. Int. 42 (2016) 16310-16316. doi:10.1016/j.ceramint.2016.07.182.

[35] H. Lahalle, C.C.D. Coumes, A. Mesbah, D. Lambertin, C. Cannes, S. Delpech, S. Gauffinet, Investigation of magnesium phosphate cement hydration in diluted suspension and its retardation by boric acid, Cem. Concr. Res. 87 (2016) 77-86. doi:10.1016/j.cemconres.2016.04.010.

[36] M. Le Rouzic, T. Chaussadent, G. Platret, L. Stefan, Mechanisms of k-struvite formation in magnesium phosphate cements, Cem. Concr. Res. 91 (2017) 117122. doi:10.1016/j.cemconres.2016.11.008.

[37] A.E. de Normalización y Certificación, UNE-EN 12467:2013 placas planas de fibrocemento: especificaciones del producto y métodos de ensayo, AENOR, 2013. https://books.google.es/books?id=OHMlngEACAAJ.

[38] A.M. Brandt, Cement-based composites: materials, mechanical properties and performance, CRC Press, 2009.

[39] N.P. Cheremisinoff, Handbook of Ceramics and Composites. Vol. 2, Mechanical 
Properties and Specialty Applications, Marcel Dekker, New York, 1992. 


\section{Tables}

Table 1. Mixture proportion of sust-MPC mortars studied.

\begin{tabular}{cccccc}
\hline \multirow{2}{*}{ Reference } & \multicolumn{2}{c}{ Solid (S) } & & & \\
\cline { 2 - 3 } & $\begin{array}{c}\text { LG-MgO/S } \\
(\mathrm{wt} \%)\end{array}$ & $\begin{array}{c}\text { MKP/S } \\
(\mathrm{wt} \%)\end{array}$ & W/S (wt $\%)$ & $\begin{array}{c}\text { MPCM/S } \\
(\mathrm{wt} \%)\end{array}$ & $\begin{array}{c}\text { AEA/S } \\
(\mathrm{wt} \%)\end{array}$ \\
\hline 0AD-0PCM & 60 & 40 & 34 & 0 & 0 \\
2AD-0PCM & 60 & 40 & 34 & 0 & 2 \\
5AD-0PCM & 60 & 40 & 34 & 0 & 5 \\
0AD-5PCM & 60 & 40 & 34 & 5 & 0 \\
2AD-5PCM & 60 & 40 & 34 & 5 & 2 \\
5AD-5PCM & 60 & 40 & 34 & 5 & 5 \\
0AD-10PCM & 60 & 40 & 34 & 10 & 0 \\
2AD-10PCM & 60 & 40 & 34 & 10 & 2 \\
5AD-10PCM & 60 & 40 & 34 & 10 & 5 \\
0AD-15PCM & 60 & 40 & 34 & 15 & 0 \\
2AD-15PCM & 60 & 40 & 34 & 15 & 2 \\
5AD-15PCM & 60 & 40 & 34 & 15 & 5 \\
\hline
\end{tabular}


Table 2. Conducted tests for each specimen.

\begin{tabular}{|c|c|c|c|c|}
\hline Shape & $\begin{array}{c}\text { Dimensions } \\
(\mathbf{m m})\end{array}$ & $\begin{array}{l}\text { Number of } \\
\text { specimens }\end{array}$ & Measured property & Specimens age (days) \\
\hline \multirow{4}{*}{ Plate } & \multirow{4}{*}{$150 \times 150 \times 35$} & \multirow{4}{*}{3} & Thermal conductivity & 7 \\
\hline & & & Thermal cycling test & 8 \\
\hline & & & Bulk density & 10 \\
\hline & & & Porosity & 10 \\
\hline \multirow{3}{*}{ Prism } & \multirow{3}{*}{$40 \times 40 \times 160$} & \multirow{3}{*}{3} & Modulus of Elasticity & 7,21 , and 28 \\
\hline & & & Compressive strength & 28 \\
\hline & & & Flexural strength & 28 \\
\hline
\end{tabular}




\section{Figure Captions}

Fig. 1. Flowsheet of the experimental measurements carried out.

Fig. 2. Thermal cycling test scheme.

Fig. 3. Thermal conductivity of TS-MPC mortars at $12^{\circ} \mathrm{C}, 20^{\circ} \mathrm{C}$ and $29^{\circ} \mathrm{C}$ as a function of weight ratio of MPCM added. (a) 0\% AEA, (b) 2\% AEA, and (c) 5\% AEA.

Fig. 4. Porosity values of TS-MPC mortars as a function of weight ratio of MPCM and AEA added.

Fig. 5. Thermal behaviour of TS-MPC mortars as a function of weight ratio of MPCM added. (a) 0\% AEA, (b) 2\% AEA, and (c) 5\% AEA.

Fig. 6. Bulk density values of TS-MPC mortars as a function of weight ratio of MPCM and AEA added.

Fig. 7. Modulus of elasticity of TS-MPC mortars at different curing days as a function of the weight ratio of the MPCM and AEA added. (a) 7 days, (b) 21 days, and (c) 28 days.

Fig. 8. Flexural strength of TS-MPC mortars as a function of weight ratio of MPCM and AEA added.

Fig. 9. Compressive strength of TS-MPC mortars as a function of weight ratio of MPCM and AEA added.

Fig. 10. SEM micrograph of TS-MPC microstructure (5AD-15PCM). 